\title{
Technical Guidelines and Prestandardization Work for First HVDC Grids
}

\section{Journal Article}

\section{Author(s):}

Akhmatov, Vladislav; Callavik, Magnus; Franck, Christian (D); Rye, Sven E.; Ahndorf, Thomas; Bucher, Matthias K.; Müller, H.; Schettler, Frank; Wiget, Roger

Publication date:

2014-02

Permanent link:

https://doi.org/10.3929/ethz-b-000080580

Rights / license:

In Copyright - Non-Commercial Use Permitted

\section{Originally published in:}

IEEE Transactions on Power Delivery 29(1), https://doi.org/10.1109/TPWRD.2013.2273978 


\section{2013 IEEE.}

Personal use of this material is permitted. Permission from IEEE must be obtained for all other uses, in any current or future media, including reprinting/republishing this material for advertising or promotional purposes, creating new collective works, for resale or redistribution to servers or lists, or reuse of any copyrighted component of this work in other works." 


\title{
Technical Guidelines and pre-standardization work for first HVDC Grids
}

\author{
V. Akhmatov, M. Callavik, C. M. Franck, S. E. Rye, T. Ahndorf, M. K. Bucher, H. Müller, \\ F. Schettler, and R. Wiget
}

Abstract--This paper presents important results of the European HVDC Study Group founded on an initiative by the German Commission for Electrical, Electronic and Information Technologies, DKE, in September 2010. The main task of the Study Group has been defining "Technical Guidelines for first HVDC Grids”: a) to gain a common understanding of basic operating and design principles of HVDC Grid Systems, and b) to prepare the ground for more detailed standardization work. The HVDC systems are moving from the stage of point-to-point (PTP) connectors to the stage of the transmission systems interconnecting more than two stations and utilizing multi-terminal (MT), multivendor (MTMV) HVDC Voltage-Sourced-Converter (VSC) systems. The development will be modular, e.g. in steps, starting with interconnecting PTP connectors and establishing three-pod, radial systems. Then, such simple systems may gradually be interconnected into radial and meshed HVDCVSC systems comprising more HVDC lines and DC converter stations. This paper describes understanding, specification and standardization of design and operation principles of the HVDC grids seen as the first needed steps towards such MTMV systems.

Index Terms-HVDC transmission, Power system control, Power system planning, Power system protection, Power system security, Short-circuit currents, Standardization, VoltageSourced-Converter, Wind power generation, Grid Code.

\section{INTRODUCTION}

A T present, with very few exceptions, HVDC systems have been built as point-to-point (PTP) connectors between AC transmission systems or being embedded into one AC system. When such AC systems are asynchronous, the HVDC

Manuscript version is June 27, 2013.

F. Schettler and H. Müller are with Siemens AG, Energy Sector resp. Infrastructure \& Cities Sector, Freyerslebenstrasse 1, 91058 Erlangen, Germany (e-mail: frank.schettler@siemens.com, hmmueller@siemens.com).

V. Akhmatov and S. E. Rye are with Energinet.dk, Transmission System Operator of Denmark, Tonne Kjaersvej 65, 7000 Fredericia, Denmark (email: vla@energinet.dk, svr@energinet.dk).

M. Callavik is with ABB Power Systems / Grid Systems, Ingenjör Bååths Gata 41, 72164 Västerås, Sweden (e-mail: magnus.callavik@se.abb.com).

T. Ahndorf is with System Analysis Asset Management, TransnetBW GmbH, Kriegsbergstraße 32, 70174 Stuttgart, Germany (e-mail: t.ahndorf@transnetbw.de).

M. K. Bucher, R. Wiget and C. M. Franck are with the EEH - The Power Systems and High Voltage Laboratories, the Swiss Federal Institute of Technology ETH, Physikstrasse 3, 8092 Zurich, Switzerland (e-mail: bucher@eeh.ee.ethz.ch,wiget@eeh.ee.ethz.ch, franck@eeh.ee.ethz.ch). technique is the only way to establish connection. Such PTP HVDC systems utilize either Line-Commutated-Converter (LCC) or Voltage-Sourced-Converter (VSC) technologies. Utilization of the LCC technology is restricted to connectors between or within AC systems with sufficiently high shortcircuit capacities at both ends. The VSC technology is suitable even for connecting islanded systems like offshore wind power plants (OWPP) to the onshore AC systems over long distances.

In 2010, the energy authorities of the ten countries of the North Sea region have enabled the North Seas Countries' Offshore Grid Initiative (NSCOGI) to find out the best way of connecting the planned over $100 \mathrm{GW}$ offshore wind power to the participating countries and establishing the offshore HVDC VSC transmission system. The main goal is the Offshore Grid infrastructure design by 2030 bringing multi-terminal, multivendor HVDC VSC transmission in focus [1].

The development towards such multi-terminal (MT) HVDC systems will be modular, e.g. in steps, [2]. The system development has begun with PTP connections and continues through simple, radial, MT systems. Such smaller systems will gradually be interconnected into larger radial and meshed HVDC-VSC systems comprising more DC terminals and HVDC links. Understanding, specification and standardization of design and operation principles of HVDC grids are seen as the first necessary steps towards such multi-terminal, multivendor (MTMV) systems.

Based on an initiative by the German Commission for Electrical, Electronic and Information Technologies, DKE, the European HVDC Grid Study Group has been founded in September 2010 to develop “Technical Guidelines for first HVDC Grids" with the objectives: (i) describing basic principles of HVDC grids with the focus on near term applications, (ii) developing functional specifications of the main equipment and HVDC Grid Controllers, and (iii) developing proposals to CENELEC EN/TS for starting standardization work. The Study Group counts members from the TSO, standardization institutions, vendors and universities: 50Hertz Transmission, ABB, ALSTOM, Amprion, DKE, Energinet.dk, ETH Zurich, National Grid U.K., Nexans, Prysmian, Siemens, Svensk Elstandard, TenneT, TransnetBW, and TU Darmstadt.

This paper presents the main results of the European HVDC Study Group elaborating typical applications and performance requirements of the HVDC grids [3]. The paper treats also the topics of principles of DC load flow and control, short-circuit currents, short-circuit fault detection and clearing, and 
required ancillary services to the adjacent AC systems.

\section{TYPICAL APPLICATIONS FOR HVDC GRIDS}

One of the first applications for MT HVDC VSC systems under discussion is the connection of large OWPP, because the main advantages can be exploited here [2]. The wind power production is subject to wind conditions, which implies that long and expensive PTP connectors are only fully utilized during relatively short periods. Fig. 1 illustrates this statement. The utilization duration for a connector like shown in Fig.1 (b) is the same as the duration curve of wind power production Fig.1 (a) [4]. The utilization of the connector can be increased if more than one AC system is connected as shown in Fig. 1 (c). During periods of low wind power generation, the connector could be used for trading electricity between the connected AC systems. The utilization can reach values close to $100 \%$, but depends on the particular situation of the two AC systems and the power capacities of the converter terminals and cable. In comparison to a topology with separate PTP connectors, so that two separate PTP connectors between the OWPP and AC System1 and between AC System1 and AC System 2, the shown in Fig. 1 (c) topology reduces the number of VSC stations, which also reduces the asset cost and maintenance.

(a)

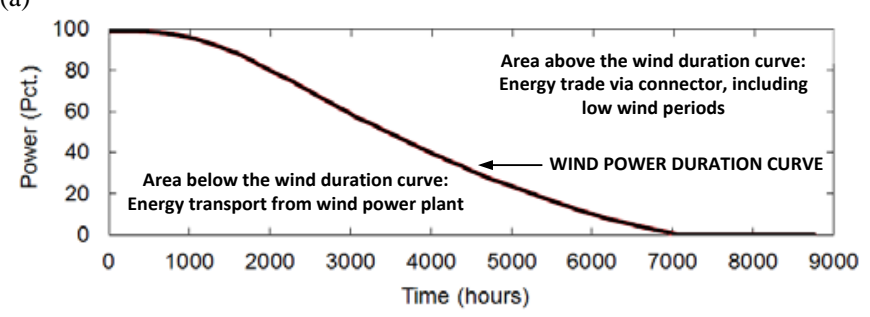

(b)

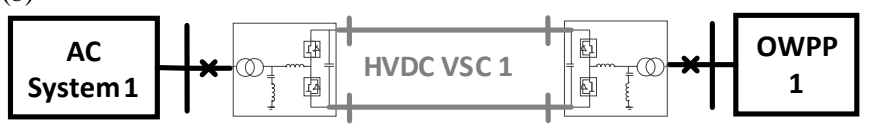

(c)

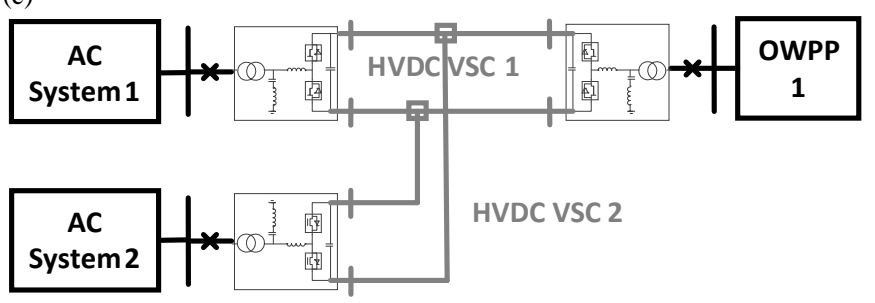

Fig. 1. Annual duration curve (a) for an offshore wind power plant in Denmark. The duration curve corresponds to the utilization of the HVDC VSC connector from the OWPP 1 to the AC system 1 according to configuration (b). An additional HVDC VSC connector according to configuration (c) allows full utilization of the interconnection arrangement, which also includes low wind periods.

\section{A. Power system planning}

An electrical transmission system, AC or HVDC, is built for exchange of energy between its nodes representing energy consumption or production. The HVDC connectors have been interpreted as part of the AC system. The VSC stations have been considered as generator-alike units obliged to provide ancillary services to the AC systems according to the Grid Codes (GC) [5]. When the HVDC grids expand in terms of dimensions and power capacity, the design, operation and reliability of the HVDC grids will be based on similar procedures and criteria as, at present, for the AC systems. Future system expansions should be considered in an early stage of system planning because such aspects influence both the electrical design and interfaces towards the DC side of the VSC stations. Among the technical aspects are selection of the nominal voltage and current as well as voltage and current control functions. In radial systems, the coordinated control of VSC stations can determine the power flow through their adjacent DC lines. In meshed MT systems, power flow distribution between parallel lines is determined by equivalent resistances and control of the VSC stations. Under these conditions, controlling the power flow through an individual line requires additional series connected power flow controllers as well as appropriate power flow monitoring and control coordination.

From the power system planning perspective, it is possible to extend the system transmission capacity at a later stage by establishing additional HVDC connections. Systems that in initial stages are built by a single manufacturer should be expandable later using equipment from other manufacturers, i.e. MTMV systems. Standardization of equipment functions, voltage levels, control and communication (protocols) will be crucial for easy and cost-efficient grid expansion and planning. For example, the voltage level in a DC grid, once selected, can only be changed at very high costs.

\section{B. Security of supply}

The grid expansion shall support agreed or predicted power and energy transmission needs and enable sufficiently high security of supply. The security of supply has a value guaranteed by the grid operator. It is determined as a product of the system adequacy and the system security.

The system adequacy is valued on the probabilistic analysis combining availability of grid components, energy production and energy capacity as well as energy demand. The system adequacy is a countermeasure to the not-delivered energy by amount and time, e.g. interruptions. Periods of not-delivered energy are defined as the time when some consumption centers do not get all required energy due to grid constraints, lack of energy production or lack of energy capacity.

The system security is the ability to maintain normal operation in cases of forced events such as, faults, failures and outages of grid components or generators. The system security is mostly analyzed for rare but severe events and stressed operation conditions, which represent the most critical situations, assigned from practical experience and expert's evaluations.

The first step to a possible HVDC grid expansion is evaluation of the grid resources with respect to the system adequacy. The common rule to evaluate the system adequacy is the compliance with the (n-1) criterion [6]. The PTP HVDC connectors are considered as generator-alike when connecting 
two asynchronous AC systems. In such a case, the PTP HVDC connectors are built as ( $\mathrm{n}-0)$ secured, i.e. outage of a single component may trip the entire connector and interrupt energy transport between the AC systems. When the PTP HVDC connectors are part of a large, synchronous AC system, it is subject to the (n-1) criterion, as it were an AC line, and its outage shall not interrupt energy transport through the remaining AC system.

The (n-1) criterion, now for the MT HVDC grids, will imply that the scheduled energy transport shall be fulfilled with a required level of the system adequacy in an outage of a DC system component or a VSC station. This may require that the HVDC lines and VSC stations are built with extra margins (temporary or permanent) to handle extra energy transport due to redistribution of power flows in such (n-1) events. Fast system reconfiguration providing alternative connection routes to transmit the scheduled power may also be needed.

When defining the system topology, the grid operators decide how to achieve the required security of supply considering (i) HVDC circuit topology, e.g. monopole or bipole connection, (ii) protection concept, including the topology of protection zones, definition of the maximum fault clearing time, establishment of a new power balance, (iii) definition of critical operation balances and events in the HVDC and adjacent AC systems, (iv) static and dynamic stability of the HVDC and adjacent AC systems, and (v) possibility of fast energization and de-energization of the HVDC system, e.g. via the VSC stations.

\section{DC LOAD-FLOW PRINCIPLES AND CONTROL}

The primary objective of an HVDC grid is to transmit power amongst its converter stations, which import power from or export power into their AC systems. To change DC power transfer, the DC voltage has to be changed accordingly. At the same time, power import into the HVDC grid tends to increase, whereas power export from the HVDC grid to decrease the DC voltage level. Transmitting power requires the DC voltage to be maintained within a certain range.

Maintaining the DC voltage means balancing the power flow and power exchange with the adjacent AC systems. In most cases, any temporary mismatch between imported and exported power will be leveled out via the adjacent AC systems according to the control characteristics of the individual converter stations. This action implies that the energy balance of each AC system is still fulfilled and the security of supply is not jeopardized. The AC systems can absorb such small, short-term power unbalance of both signs due to the system inertias. The short-term power unbalance with the AC systems is tolerable as far as it does not lead to their energy unbalance or affects negatively the frequency quality and security, e.g. due to a lack of inertia. In severe cases, the power surplus can be stored in energy storages, which at a present development stage are costly, or turned into heat using Dynamic Braking Devices, sometimes also referred as DC Choppers. Energy storages will also have to compensate power deficit to keep the DC voltage within a required operation range when it is more favorable than importing extra power from the AC systems.

The control functions can be differentiated with respect to their purpose and dynamics into fast local VSC Station Control and slower superordinate HVDC Grid Control. Fig. 2 shows a signal flow example between the VSC Station Controllers and the HVDC Grid Controller for a radial HVDC grid.

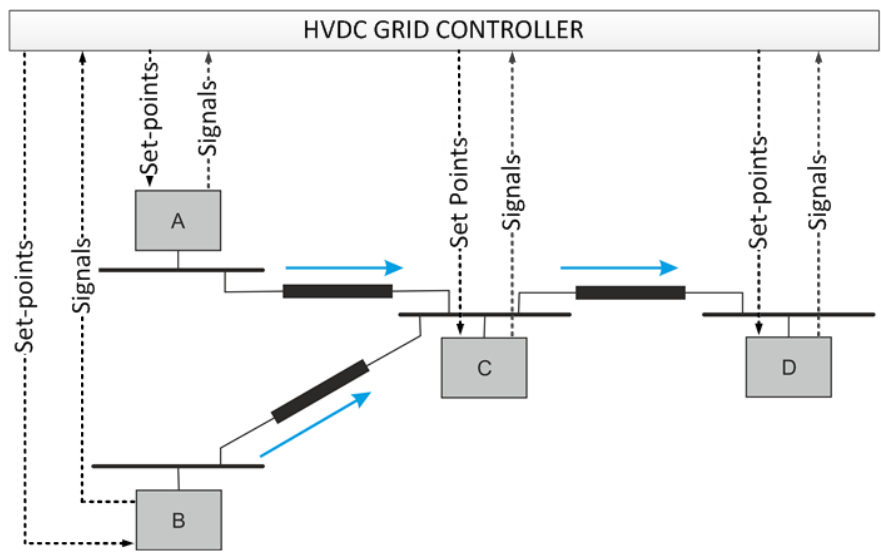

Fig. 2. Signal flow diagram between the HVDC Grid Controller and four Station Controllers of the VSC stations A, B, C, and D. Set-points may comprise requested operating mode, i.e. power, voltage or frequency, power order, local DC voltage reference, voltage droop characteristics, power droop for DC voltage controlling VSC station (optional), dead bands for DC voltage (optional), dead bands for power (optional), end value and time of change values for DC voltage and power. Signals to the HVDC Grid Controller may comprise measured DC voltage, DC current and power as well as AC voltage, AC current, apparent power and frequency.

\section{A. VSC Station Controllers}

The VSC Station Controller handles the given VSC operation point, i.e. controlling the voltages and currents at the DC and AC terminals with the response time typically in a range of tens microseconds. The control objectives can be to keep a certain active power flow via the VSC station, AC system frequency, DC voltage, and can independently control reactive power exchange with the AC system, or AC voltage. In general, the VSC Station Controller does not rely on external communication. Mutual coordination between the VSC stations and the DC and AC systems can be achieved applying pre-determined characteristics, such as fixed reference values and droop characteristics. Nonetheless, it sends status and measuring signals to the HVDC Grid Controller and receives its control characteristics and reference values, accordingly to the example of Fig. 2.

The control mode of a VSC station can be distinguished either by the direction of the active power flow, i.e. the rectifier or inverter mode, or by the type of control reference signal. When operated in "DC voltage control mode", it has to adjust its active power exchange with the AC system to meet the given DC voltage reference value. The active power exchange of this particular VSC station with the AC system is adjusted to balance the power in the DC system. Thus, this VSC station operates as the swing-bus of the DC system, e.g. absorbing any power unbalance of the HVDC system and exchanging the unbalance with the adjacent AC system. The response time is defined by the HVDC system ability to 
dynamically maintain the DC voltage within required operation ranges in each VSC station. The response time to handle power unbalance and ability to maintain the DC voltage ranges shall be among the technical specifications to the HVDC systems, which include specifications to existing as well as planned for commissioning VSC stations. The response time range can be up to a few $100 \mathrm{~ms}$, but depends on the DC capacitance of the HVDC system components, i.e. the DC voltage sensitivity, and on the control system constraints to power flow changes.

When a VSC station operates in "active power mode", it adjusts its DC voltage to enable the active power transport meeting the active power reference value within the operational DC voltage limits. The VSC station will be required to participate in the primary frequency control of the adjacent AC system, which can either be a frequency-sensitive mode or a frequency-limiting-mode [5]. The VSC station shall be commissioned to handle both frequency control modes, but activated one at a time. The requested frequency control mode activates and overrules the regular active power mode when frequency deviations exceed a normal-operation frequency range. The normal-operation frequency range as well as the parameters of the frequency control modes are defined by the TSO of the adjacent AC system, usually in the Grid Code. Since the HVDC system only transports, but does not produce or store electric energy, activation of the frequency control of the VSC station in one of the adjacent AC systems may influence the frequency quality in other adjacent AC systems. Thus activation rules and parameters of the frequency control modes shall be agreed between the relevant TSOs. The characteristic response time is in a range from few to tens seconds. In practice, the active power reference value will comprise a contribution provided by a secondary control loop, i.e. controlling the $\mathrm{AC}$ frequency, which is added to the control signal of the primary control loop in order to produce the power reference value of the VSC station [5].

Regardless which control modes are applied, the reference values of the VSC Station Controllers can be either a fixed value, without or with a dead band, or follow a droop characteristic, within a certain range.

\section{B. HVDC Grid Controller}

The HVDC Grid Controller is a higher level controller linked to each individual VSC Station Controller. Its main purpose is to provide the VSC Station Controllers with their control characteristics and reference values; this is illustrated in Fig. 3 for the case of a small, radial HVDC system. The HVDC Grid Controller is factored with the static, as-built information on the HVDC system topology and electric parameters, such as resistances and maximum ratings. Therefore, the HVDC Grid Controller shall also facilitate grid restoration when the grid has split up after the fault clearance.

In order to monitor and optimize the power flow and assure the compliance to the (n-1) criterion [6], it receives the current status, e.g. in- or out-of-service of lines, cables, VSC stations, HVDC switchgear and breakers, and, possibly, availability of energy storages and DC choppers, and measuring signals from the VSC Station Controllers and vital HVDC gridcomponents. Through the interface to the system operators, it receives the (scheduled) power dispatches from the system operators. Additionally, it receives the information on scheduled revision plans for the grid-components. Hence, its operation relies on reliable communication with the VSC Station Controllers and system operators.

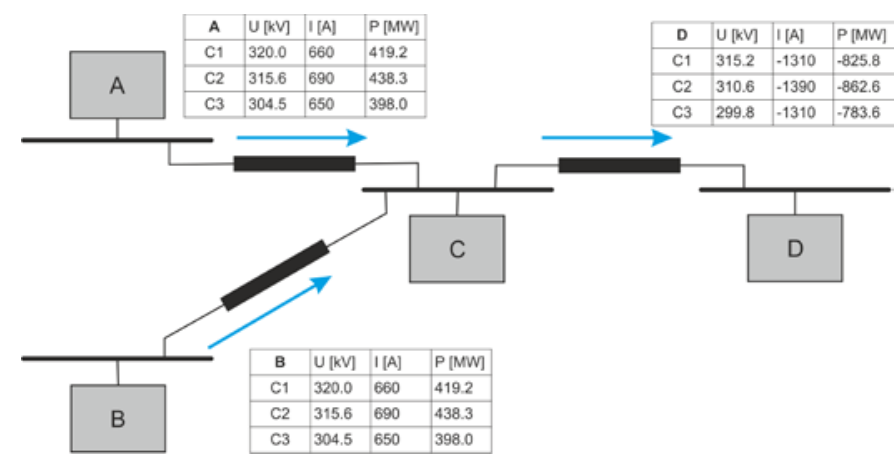

Fig. 3. Benchmark DC grid configuration and stationary power flow values after a sudden loss of terminal C.

When all information is made available for the Controller, it performs the power-flow pre-calculation which is similar to the load-flow study for a conventional AC network. The security-of-supply, i.e. the compliance to the (n-1) operation criterion, is assured using contingency analysis in a similar way as for AC networks. The calculations shall prove that the given voltage ranges will not be violated and the given current ratings (converters and lines/cables) will not be exceeded in normal operation as well as in (n-1) contingencies.

Reliability of the HVDC system operation must also be ensured if the HVDC Grid Controller fails; the failure is either due to outage or loss of communication to some or all gridcomponents. In the latter case, the affected VSC Station Controllers will act autonomously. It is not any longer possible or necessary to keep an optimized power flow, but the DC voltage must be kept within a required operation range. The HVDC system must remain stable until the normal operation of the HVDC Grid Controller is re-established.

The other way can be to keep a redundant HVDC Grid Controller on another physical location. The redundant Controller would be a mirror of the main HVDC Grid Controller and take over its functions in outage or physical damage, e.g. in case of fire, of the main Controller.

\section{DC load-flow control concepts}

The main target is that different concepts for the HVDC Grid Controllers and the VSC Station Controllers are applicable together within MTMV HVDC systems. The fact that converter controls are often considered intellectual property can make exchange of information difficult. This apparent barrier towards MTMV HVDC systems can be overcome through definition and standardization of the common control concepts and the common lists of parameters. The following three control concepts are favored by the 
vendors participating in the European HVDC Study Group as the common ones: $\mathrm{C} 1$ - voltage-power droop together with dead band (VPDDB), C2 - voltage-current droop (VCD), and C3 - voltage-power droop (VPD) [7], [8], [9].

Since the MT HVDC grid will be realized as a multi-vendor system, it must remain statically and dynamically stable regardless which of the control concepts is applied to a certain station. To demonstrate this requirement, benchmark simulations of the four-terminal system in Fig. 2 have been performed. In the described benchmark simulations, the stationary power ratings of the VSC stations are $800 \mathrm{MW}$, the nominal operational voltage is $\pm 320 \mathrm{kV}$, and the VSC stations are connected via symmetric monopolar links comprising XLPE cables, $200 \mathrm{~km}$ length each.

In the initial steady-state situation, VSC stations A and B are rectifiers, i.e. importing $800 \mathrm{MW}$ each into the HVDC system, whereas VSC stations C and D are inverters, i.e. exporting $775 \mathrm{MW}$ at $\mathrm{C}$ and $800 \mathrm{MW}$ at $\mathrm{D}$.

The total benchmark simulations comprise different power loss situations, i.e. outages of different VSC stations. The following example shows the case of a total load rejection, so that outage of the VSC station C. The outage leads to a surplus of 775 MW imported into the HVDC system. This condition is, first, handled by the local VSC Station Controllers which remain in-service, because the HVDC Grid Controller cannot react in such a short time-frame. The three common control concepts, C1 to C3, have coped with this extreme situation. The tables in Fig. 3 show the post-event stationary power flow situation for all three common concepts, after the transients have decayed. In all three concepts, the power loss is compensated by an equal reduction of the power import via the VSC stations A and B. The difference is that the final steadystate of the control concept $\mathrm{C} 1$ reaches the maximum voltage limit at the importing VSC stations and a final power flow of $825 \mathrm{MW}$, and the lower voltage limit is reached for C3 at the VSC station D with the final power flow of only 784 MW.

The simulation study has concluded that different control concepts of VSC Station Controllers should work together in a stable manner. The study has, however, applied generic-level models and parameters of the Controllers. The converters in general have non-linear voltage-current characteristics and principles of superposition should be used with great care only. Application of vendor-specific parameters and control concepts in a network with multiple concepts is recommended to study the stability. Based on this first study the following functional specifications for "control interaction" was formulated:

- Generally, it is recommended to design the system considering different levels of detail.

- In high level approach, dominant frequencies existing in the HVDC Grid shall be identified by simulations or measurements, if the system already exists. DC network harmonic impedances shall be calculated for all relevant network conditions. Harmonic voltage levels and network harmonic impedances shall be specified allowing measures to be taken to avoid critical resonance conditions.

- In a more detailed approach, time domain simulations shall be carried out investigating possible interactions between the individual converters including their controls. Appropriate transient models of the existing converters shall be provided allowing measures to be taken to avoid control instabilities.

Additionally, the interface between the HVDC Grid Controller and the local VSC Station Controllers influences the response of the entire HVDC system to a disturbance. The interface shall clearly define how fast and how exact the reference values sent to the VSC Station Controllers are met, i.e. whether an offset is permitted in the final response due to a dead-band or a droop.

The interface shall also contribute to cancelation of the control hunting risk, i.e. avoiding that the VSC Station Controllers work against each other. The interface shall contribute to inherent dynamics of the VSC stations in order to reach the desired common response of the HVDC system. Commonly defined response parameters, e.g. for a step change in the operation conditions, could serve this purpose.

\section{DC SHORT-CIRCUIT FAULTS AND PROTECTION}

The protective clearance and removal of a short-circuit fault have three important purposes:

- Minimizing hazard to personnel;

- Minimizing disturbance to system operation;

- Minimizing risks of equipment and buildings' damage.

The protection systems shall be selective and trigger on a fault within its protective zone as well as not operate for faults outside its zone. Fig. 4 illustrates, in general, a VSC station protective zones distinguishing: (i) the converter station protective zone, shown by marks 1 and 2, (ii) the AC system protective zone, mark 3 , and (iii) the HVDC grid protective zone, mark 4. Furthermore, the converter station protective zone shall distinguish between faults on the DC terminals, mark 1, and the AC terminals, mark 2.

\section{A. Converter station protections}

Fig. 5 shows a common protection scheme of a symmetrical monopole VSC station. An asymmetrical VSC station will have additional settings for the DC voltage unbalance. Bipolar schemes are commonly designed with independent protection systems between the poles, so that as for two asymmetric monopoles. The VSC station protections in Fig. 5 are grouped by the three main zones.

The protective zone related to the HVDC Grid System, i.e. by mark 4 in Fig. 4, comprises:

-DC line voltage unbalance protection detecting deviations between positive and negative DC line voltage to ground;

-DC line over- and under-voltage protection detecting such violations in either positive or negative DC line voltage to ground. 
The VSC station protective zone, which is coordinated by the converter design and by marks 1 and 2, includes:

-DC link over-current protection;

-DC current differential protection detecting ground faults on the DC converter terminals or within the circuit up to the converter transformer;

- Busbar current differential protection detecting deviations between the sum of converter arm currents and the DC current at positive and negative DC busbars;

- Asymmetry protection objecting to detect single-phaseground faults at the AC converter terminals;

- Converter / valve reactor over-current protection, i.e. in any of the six converter limbs;

- AC secondary / limb current differential protection objecting to detect faults between the limb reactors and the converter transformer;

- AC secondary under-voltage protection, i.e. at the AC converter terminals;

- Pre-insertion resistor over dissipation protection detecting excessive energy dissipation through the pre-insertion resistor.

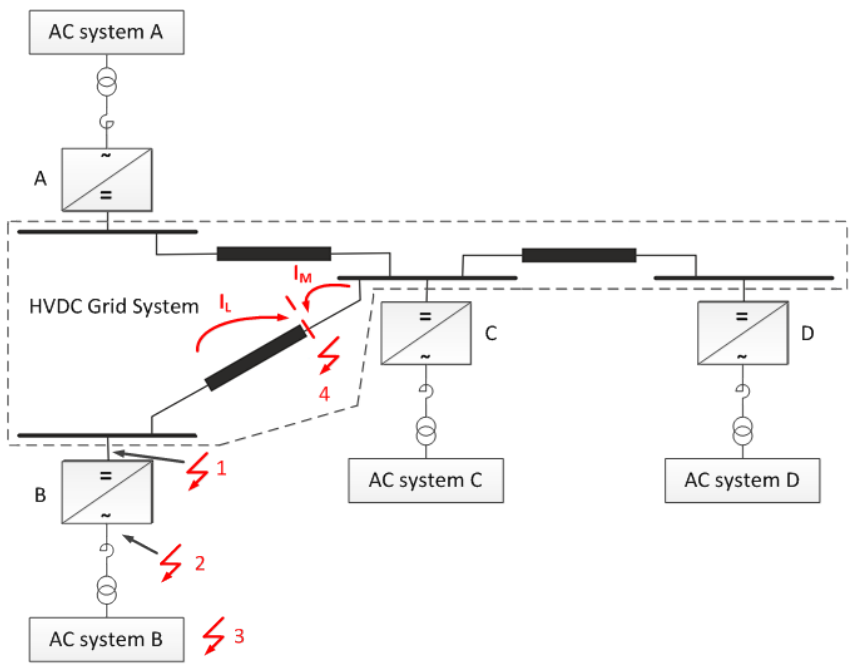

Fig. 4. Illustration of a converter station protective zones and a short-circuit current in a radial MT HVDC grid topology.

The AC system protections, i.e. by mark 3, include:

- AC over- and under-voltage protection detecting longduration AC system faults;

- AC over- and under-frequency protection.

The operation of any of the above protections will initiate a block and trip of the VSC station, with exception of where the fault-ride-through capability or ancillary services to the AC grids are required by the Grid Code [5].

\section{B. DC short-circuit current}

The HVDC grid structure itself has a significant impact on the maximum possible amplitude of the DC short-circuit current, i.e. the fault current level. The concentrated filter capacitances and the distributed capacitances of the connecting cables and lines discharge during a fault and lead to a first transient short-circuit current.

Later, a steady-state short-circuit current establishes that is mainly determined by the contributions of the converter stations [10], [13]. Similarly to AC grids, the maximum amplitude of the steady-state DC short-circuit current rises for a higher number of converter stations. In contrast to AC grids, the transient phase strongly depends on the exact fault location, the distributed and concentrated capacitances connected to the faulted line and the fault impedance. Fig. 4 (marks 4) shows a radial MT HVDC grid structure subject to a DC short-circuit fault on the line of converter station B. The short-circuit current has the two main contributions: (i) the line short-circuit current, $I_{\mathrm{L}}$, and (ii) the short-circuit current, $I_{\mathrm{M}}$, from the DC line interconnection point.

\section{HVDC grid fault detection and clearing}

Since an HVDC Grid System comprises several converter stations, it requires more selectivity in the DC protection than conventional PTP HVDC transmission links with two converter stations. The selectivity shall allow both identification and subsequent removal of a faulty part and permit continued operation of the remainder of the HVDC Grid System. The protection system design shall acknowledge the following topics in detail: (i) the HVDC grid structure, (ii) behavior of converters for earthing- and short-circuit faults, (iii) operational conditions prior to a fault, (iv) fault types, i.e. converter faults, AC system faults, HVDC grid faults, (v) utilization of HVDC breakers, and (vi) impact from communication.

The HVDC grid protections are dependent upon the specific needs on the detection, isolation and selectivity of the grid following a short-circuit fault. The grid operator shall define whether fast dynamic isolation of a DC short-circuit fault is needed. Where there are no needs for fast dynamic isolation, a temporary stop is accepted for manual control of reconfiguration of the HVDC Grid System after a fault. Such a temporary stop is acceptable for small HVDC systems and where it does not jeopardize security of supply and stability of any of the adjacent AC systems. The fault isolation time is categorized accordingly to the required breaking device type [9][10], [11], [12]:

- Faster than few milliseconds requires a fast isolation device that can be an HVDC breaker based on power electronic devices or hybrid ones which also incorporate mechanical devices [11];

- Faster than 100 milliseconds needs mechanical HVDC breakers;

- Faster than few seconds needs so-called High Speed Switches, i.e. conventional AC breakers to interrupt the current in-feed from the AC converter terminals into the DC short-circuit fault.

- The specific needs for the fault isolation time are dependent on the specific operation requirements for the adjacent AC systems as well as on the VSC topology. If loosing of the VSC station is critical for security of supply, i.e. active power transport, and stability, i.e. 
ancillary services, of an adjacent AC system, the use of fast isolation devices in right positions of the HVDC Grid System shall be considered.

The VSC topology shall be taken into consideration for evaluation of investment needs into fast isolation devices. The evaluation is based upon the requirement for the specific system to minimize the impact on security of supply and stability of the entire AC and HVDC power systems:

- In case of the VSC-based half bridge converters with no fast isolation agent, the IGBT switches are blocked and the DC fault current is supplied through inherent uncontrolled diode bridges. The DC fault current is cleared by the AC breakers of all converters.

- For the VSC-based full bridge converters, the fault current is suppressed by the converter control actions. Hence, high-speed switches can be utilized with such converters for interruption of the DC fault current. The use of high-speed switches will depend on the response time required to maintain stable operation of the power system.

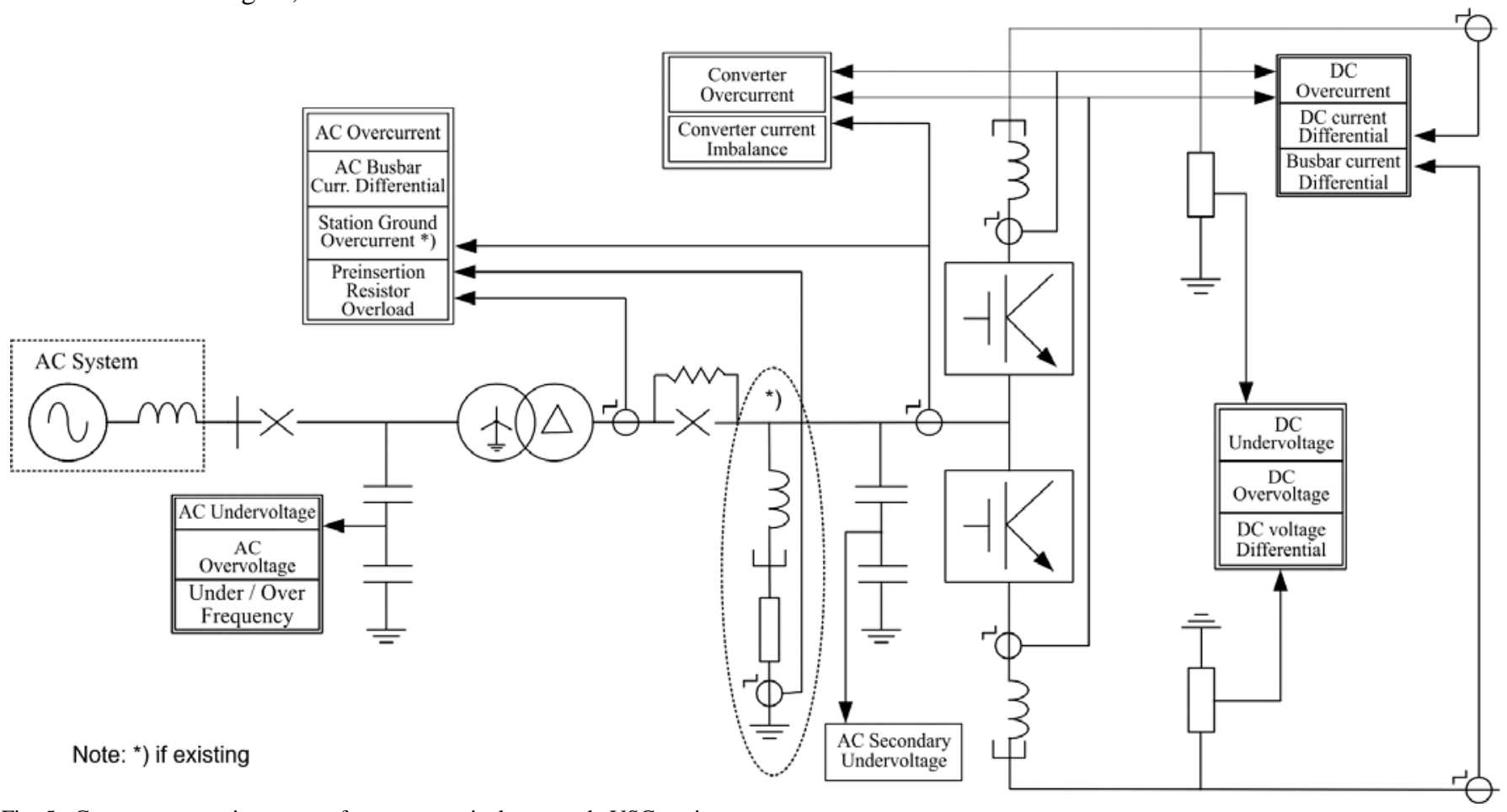

Fig. 5. Common protection system for a symmetrical monopole VSC station.

-When fast isolation devices, for example HVDC Breakers [11], are added in series with the VSC-based half bridge (or full bridge) converters, the DC fault currents are cleared selectively by the corresponding fast dynamic isolation device so that the healthy part of the HVDC system remains in operation.

\section{CONCLUSION}

This paper is based on the work conducted by the European HVDC Grid Study Group and presented some central items from the Study Group Report "Technical Guidelines for first HVDC Grids”. The work of the Study Group has determined important application and performance requirements to future multi-terminal, multi-vendor HVDC grids. Such multiterminal, multi-vendor HVDC grids could be attractive solutions for connecting offshore wind power with onshore DC and AC systems in the future.

The work has concluded that standardization of functional requirements for equipment, controls, communication and interfaces, will enhance the development of HVDC connections generally, and multi-terminal HVDC grids in particular.

HVDC grid development and expansion is expected to be modular, i.e. stepwise development, from the present point-topoint or three-pod HVDC terminal configurations. Existing HVDC systems will gradually expand and become multiterminal radial and meshed HVDC grids. The planning and expansion of HVDC grids need to be in compliance with the design and operation criteria for the present AC transmission systems connected. The expansion design and planning shall secure both the right level of security-of-supply and facilitation of the HVDC grid with needed control principles. For successful expansion of a single-vendor system to a multivendor HVDC grid, a number of technical principles are found essential with the objective in mind: getting the HVDC Grid Controller and the local VSC Station Controllers to work right away as easy as if it were a-single-vendor, point-to-point HVDC connection.

The simulation study, which applied generic-level models and parameters of the Controllers, has shown that different 
control concepts of VSC Station Controllers should work together in a stable manner. Application of vendor-specific parameters and control concepts is recommended to study the stability of physical HVDC grids.

The Study Group has identified the voltage-power droop together with dead band (VPDDB), the voltage-current droop (VCD), and the voltage-power droop (VPD) as suitable common control concepts of the VSC Station Controllers. Furthermore, the selection of a HVDC Grid Controller is proposed for operating the individual VSC Station Controllers, each with different modes or concepts that will work together. The interface control principles and lists of required parameters shall be appropriately identified and standardized in order to achieve optimized power-flow for each DC terminal added to the HVDC system.

The Study Group has also identified the need for standardization of short-circuit current calculation methods, earthing and fault handling principles within HVDC grids. The short-circuit calculation methods and principles shall take the contributions from adjacent AC systems into account, which are not infinitely stiff AC systems.

\section{REFERENCES}

1] ENTSO-E / European Network of Transmission System Operators for Electricity, "Offshore Transmission Technology ", Prepared by the Regional Group North Sea for the NSCOGI (North Seas Countries' Offshore Grid Initiative), Nov. 24, 2011, 44 p.

[2] ENTSO-E / European Network of Transmission System Operators for Electricity, "The North Seas Countries' Offshore Grid Initiative - Initial Findings ", Final Report Working Group 1 - Grid Configuration, Prepared by the Regional Group North Sea for the NSCOGI (North Seas Countries' Offshore Grid Initiative), Nov. 16, 2012, 142 p. Available: http://www.benelux.int/nscogi/NSCOGI_WG1_OffshoreGridReport.pdf

[3] DKE / German Commission for Electrical, Electronic and Information Technologies, "Technical Guidelines for first HVDC Grids ", Prepared by the European HVDC Grid Study Group, Sept. 24, 2012, 102 p.

[4] EWEA / European Wind Energy Association, "Wind Energy - The Facts. A guide to the technology, economics and future of wind power ", Earthscan, London, U.K., 2009, 568 p.

[5] ENTSO-E / European Network of Transmission System Operators for Electricity, "Network Code for Requirements for Grid Connection Applicable to all Generators ", June 26, 2012, 81 p.

[6] ENTSO-E / European Network of Transmission System Operators for Electricity, "Standards for European Transmission Grid Planning", Approved by the SDC / System Development Committee, Nov. 18, 2010, 13 p.

[7] C. D. Barker and R. Whitehouse, "Autonomous converter control in a multi-terminal HVDC system," in Proc. 2010 ACDC. 9 ${ }^{\text {th }}$ IET International Conference on AC and DC Power Transmission, London, U.K., Oct. 19-21, 2010, 5 p.

[8] O. Gomis-Bellmunt, J. Liang, J. Ekanayake, R. King, N. Jenkins, "Topologies of multiterminal HVDC-VSC transmission for large offshore wind farms," Lancet, vol. 81, no. 2, pp. 271-281, 2011.

[9] E. Prieto-Araujo, F. D. Bianchi, A. Junyent-Ferre, O. Gomis-Bellmunt, "Methodology for Droop Control Dynamic Analysis of Multiterminal VSC-HVDC Grids for Offshore Wind Farms," IEEE Trans. Power Delivery, vol. 26, no. 4, pp. 2476-2485, 2011.

[10] M. K. Bucher, M. M. Walter, M. Pfeiffer, C. M. Franck, "Options for Ground Fault Clearance in HVDC Offshore Networks ", in Proc. IEEE Energy Conversion Congress and Exposition, Raleigh, NC, USA (2012).

[11] J. Hafner, B. Jacobson, "Proactive Hybrid HVDC Breakers - A key innovation for reliable HVDC grids," CIGRE-2011 Symposium, Bologna, Italy, Paper 264.

[12] C. M. Franck, "HVDC Circuit Breakers: A Review Identifying Future Research Needs," IEEE Trans. Power Del., 26(2), 998-1007 (2011).
[13] M.K. Bucher, C. M. Franck, Contribution of Fault Current Sources in Multiterminal HVDC Cable Networks, IEEE Trans. Power Del., 28(3), 1796-1803 (2013).

\section{BIOGRAPHIES}

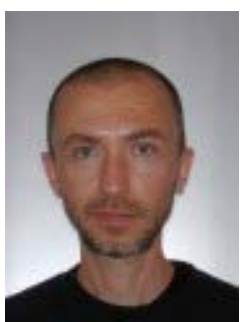

Vladislav Akhmatov received his $\mathrm{MSc}$ and $\mathrm{PhD}$ from the Technical University of Denmark in 1999 and 2003. He has been with the Danish power company NESA, now part of DONG Energy, Siemens Wind Power A/S first as an engineer and later as a Chief Specialist, the Center for Electric Technology, the Technical University of Denmark, as a Professor with special responsibilities in Electric Power Systems, before he returned to Energinet.dk in 2010, the Danish TSO, as a Senior Engineer, Emeritus Professor. In 2006 he received the Electro Award (Elektroprisen-2006) of the Danish Engineers' Society for grid-integration of wind power in Denmark.

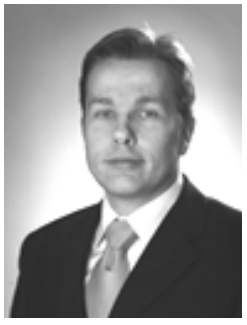

Magnus Callavik (M’2009) was born in Sweden on April 19, 1969. He graduated from the Royal Technology of Technology, Stockholm (MSc 1994, $\mathrm{PhD}$ 1998), and was a Research Fellow at Stanford Research Institute in California during 1994. He holds an Executive MBA from Stockholm School of Economics (2009) and is a certified project management professional (PMP). He was employed at ABB in 1999. During the last years he has held $\mathrm{R} \& \mathrm{D}$ and laboratory test management positions at ABB Corporate Research. Since 2010 he is program manager for HVDC Grids at ABB Power Systems. He is a board member of KIC Innoenergy and the Swedish National Committee for IEC and Cenelec.

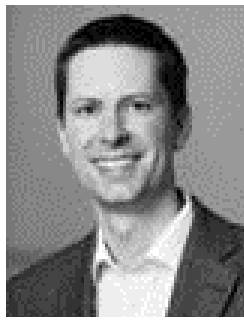

Christian M. Franck (M’04, SM'11) received a diploma in physics from the University of Kiel, Germany in 1999 and $\mathrm{PhD}$ in physics from the University of Greifswald, Germany in 2003. He was with the Swiss corporate research center of ABB from 2003-2009 as a Scientist and Group Leader for gas circuit breakers and high-voltage systems. Currently, he is Assistant Professor for High Voltage Technology at the Swiss Federal Institute of Technology (ETH), Zurich, Switzerland.

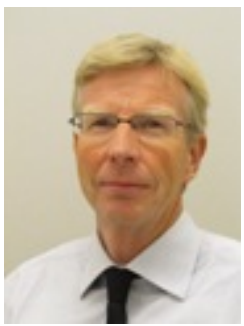

Sven E. Rye is born in Norway on July 25, 1958. He graduated from the Norwegian Institute of Technology (NTNU) in Trondheim in 1983. Employment experience includes offshore and onshore energy companies: Kvaerner and Norsk Hydro in Norway, ENI in Italy, Maersk and Energinet.dk, TSO for natural gas and electricity in Denmark. Specialty fields are energy projects development and project management.

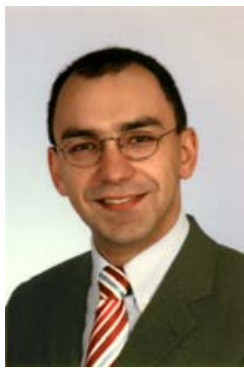

T. Ahndorf Thomas Ahndorf (M‘2006) was born in Heilbronn, Germany on October 11th, 1977. In 2004 he received his diploma in electrical power engineering and automation from the University of Applied Science in Karlsruhe, Germany. After this he started a postgraduate study also at the University of Applied Science in Karlsruhe and received his M.Eng. in Electrical Engineering in 2006 with distinction. From 2006 to 2010 he worked at the Associated Institute of Power Transmission Systems of Technische Universität München as a PhD student. His research focused on the grid connection of large scale offshore wind power with HVDC and system dynamics. Since 2010 he is working at TransnetBW GmbH (German TSO) and is currently senior manager in field of system analysis, a member of German VDE. 


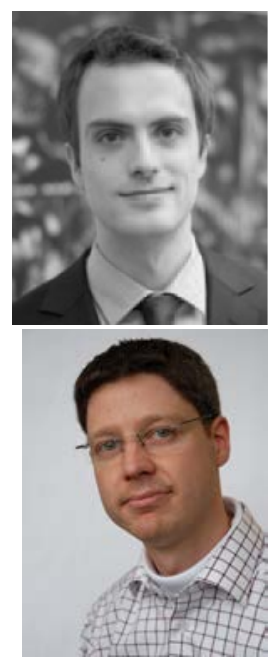

M. K. Bucher (S'12) received his BSc degree and MSc degree in electrical engineering from the ETH Zurich, Switzerland, in 2009 and 2011, respectively. He joined the High Voltage Laboratory of ETH Zurich in 2011, where he is currently working towards a $\mathrm{PhD}$. His research is dedicated to transients in multi-terminal HVDC networks.

transmission, distribution and industrial networks.

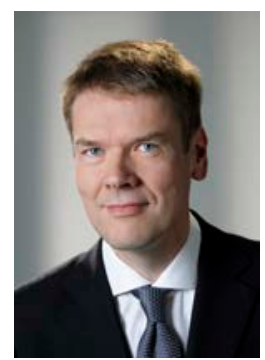

Frank Schettler received his Dipl.-Ing. and $\mathrm{PhD}$ in Electrical Engineering from the Technical University of Ilmenau, Germany in 1992 and 2003 respectively. He has been working with Siemens in the field of power transmission for about 20 years. Working on numerous projects worldwide, he gained experience in the fields of power system design, development, application engineering and sales of HVDC systems, FACTS and Grid Access Solutions. He used to be head of system engineering for Siemens' FACTS and Grid Access Solutions before he entered into his current position to be the Portfolio Manager for HVDC and Grid Access technology, where he is responsible for the technology portfolio of Siemens in these fields. Frank Schettler is the convener of the European HVDC Grid Study Group (DKE/CENELEC) and was chair of the working group Technological within FOSG in 2011.

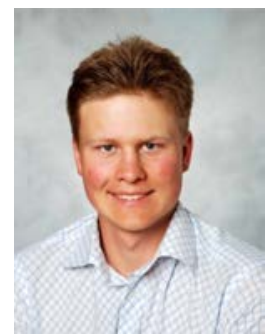

Roger Wiget (S'11) is born in Lucerne, Switzerland. He received his BSc degree in electrical engineering and MSc degree in Energy Science and Technology from the ETH Zurich, Switzerland, in 2009 and 2011. He joined the Power Systems Laboratory of ETH Zurich, Switzerland in 2011 where he is working towards a $\mathrm{PhD}$. His research is dedicated to HVDC networks. He is a student member of the IEEE. 